\title{
LONG-TERM SURVIVORSHIP AND CROWN AREA DYNAMICS OF TROPICAL RAIN FOREST CANOPY TREES
}

\author{
Stanley R. Herwitz, ${ }^{1,4}$ Robert E. Slye, ${ }^{2}$ and Stephen M. Turton ${ }^{3}$ \\ ${ }^{1}$ Graduate School of Geography and Department of Biology, Clark University, Worcester, Massachusetts O1610 USA \\ ${ }^{2}$ Ecosystem Science and Technology Branch, NASA/Ames Research Center, Moffett Field, California 94035 USA \\ ${ }^{3}$ Department of Tropical Environmental Studies and Geography, James Cook University, Cairns, \\ Queensland 4870 Australia
}

\begin{abstract}
Lateral shading of direct-beam irradiation among neighboring canopy tree crowns in a nonequatorial tropical rain forest canopy was modeled as a function of solar position using a photogrammetric database derived from large-scale color aerial stereopairs (1:1500-1:3000 scale) acquired in 1976. The interception of direct-beam irradiation by the orthogonally projected crown area of each tree was computed at hourly intervals over a full calendar year using a Parameterization model of cloud-attenuated direct-beam availability. The annual totals of intercepted direct-beam irradiation $\left(I_{\mathrm{b}}\right)$ ranged from 1.81 to $4.13 \mathrm{GJ} \cdot \mathrm{m}^{-2} \cdot \mathrm{yr}^{-1}$. Expressed as a percentage of the available incident direct-beam irradiation, these values ranged from $44 \%$ to $100 \%$. Approximately $20 \%$ of the sample population intercepted $<70 \%$ of the available annual direct-beam irradiation. The long-term effects of lateral shading and the intertree differences in $I_{\mathrm{b}}$ were assessed using repeat aerial stereophotography of the same section of forest 18 yr later in 1994 for the determination of the mortality, survivorship, and crown growth of the canopy trees delimited in the 1976 stereopairs. Mortality over the 18-yr period amounted to $27.2 \%$. Based on the lateral shading simulations, the mean annual $I_{\mathrm{b}}$ totals of the survivors and those that died were significantly different $(P<0.001)$. Approximately $40 \%$ of the survivors experienced crown area reductions. Although there was no significant difference in the $I_{\mathrm{b}}$ of survivors with crown growth and those with crown reductions, a relationship was established between $I_{\mathrm{b}}$ and the extent of crown area change. Canopy trees that intercept the most direct-beam irradiation and experience the least lateral shading have higher probabilities of survivorship and significant crown area changes that may be in the form of crown growth or crown reduction. Their laterally shaded neighbors have a lower survivorship probability, and those that survive persist in an inhibited state with limited crown area change. We conclude that the effects of lateral shading are not limited to the margins of treefall gaps and that lateral shading determined by crown position in the uneven upper canopies of nonequatorial tropical rain forests has a detectable effect on the long-term fates of neighboring canopy trees.

Key words: aerial stereopairs; canopy trees; crown dynamics; crown position; direct-beam interception; lateral shading; mortality; survivorship; 3-D model; tropical rain forest.
\end{abstract}

\section{INTRODUCTION}

Studies of plant competition examine the ways in which plants may limit resource acquisition by neighboring plants. In closed-canopy tropical rain forests, where cloud cover is common and solar irradiation is often a limiting resource (Yates et al. 1988), a competitive advantage is gained by those trees that cast the most shade and intercept the most solar irradiation ( $\mathrm{Gi}$ vinish 1988, Chazdon et al. 1996). Competition for solar irradiation has been characterized as an overtopping game in which rapid vertical growth (monopodial extension) is followed by horizontal crown spreading (sympodial branching) (Givinish 1984, Kuuluvainen 1992). The shadows generated by trees that have

Manuscript received 29 April 1998; revised 24 November 1998; accepted 23 December 1998; final version received 14 January 1999.

${ }^{4}$ E-mail: sherwitz@clarku.edu reached upper canopy positions have been considered mainly in the form of subcanopy light attenuation. Well documented is the attenuated light regime within and beneath crowns (Chazdon and Fetcher 1984, Oberbauer and Strain 1986, Oberbauer et al. 1988, Canham et al. 1990, Smith et al. 1992, Pearcy and Yang 1996) and the scavenging of short-duration sunflecks by seedlings, saplings, and other understory plants (Augspurger 1984, Langenheim et al. 1984, Chazdon and Pearcy 1986, Chazdon 1988, Pearcy 1990, King 1994). Less well understood are the effects of the lateral shadows cast among neighboring canopy trees whose crown height differences often exceed 5-10 m. These height differences, which account for the characteristic roughness of tropical rain forest canopies (Richards 1952, Longman and Jeník 1974), have been previously considered in relation to wind turbulence and the exchange of water and heat through the forest boundary layer (Oldeman 1978, Pinker and Holland 1988, Herwitz and Slye 1995). 
Canopy trees are here defined as having fully exposed crowns that would intercept the same quantity of direct-beam solar irradiation per unit orthogonally projected crown area when the sun is at its zenith position. These same trees, however, may intercept significantly different quantities of direct-beam irradiation per unit crown area when the sun is at lower elevation angles because of the lateral shadows cast by more prominent neighboring crowns. At high latitudes, isolated trees generate significant midday light depletion zones due to the long shadows that they cast at low sun elevations (Kuuluvainen and Pukkala 1987). One might assume that lateral shading is not a factor in tropical latitudes because of higher midday solar elevations; however, in the nonequatorial tropics (15-23 $\mathrm{N}$ and $15-23^{\circ} \mathrm{S}$ ), there is a distinct seasonality in midday solar position between the summer and winter solstices (Turton 1988). At $17^{\circ} \mathrm{S}$ latitude, for example, midday solar elevations never exceed $55^{\circ}$ during June and July. Under these conditions, lateral shading would be expected among neighboring canopy trees not only during the early morning and late afternoon hours, but also at midday.

In this paper, we examine the spatial and temporal variation in lateral shading among neighboring canopy trees in a nonequatorial tropical rain forest, and then consider its long-term effect on survivorship and crown growth. According to Young and Hubbell (1991), canopy trees subject to lateral shading at the margins of treefall gaps commonly exhibit a shade avoidance response in the form of asymmetric crown development. This tendency to grow away from shadows cast by taller neighbors and towards the light associated with the adjoining gap results in an uneven distribution of mass in their crowns and an increased frequency of tree toppling along the margins of existing treefall gaps (Lawton and Putz 1988, Young and Perkocha 1994). Given the characteristic roughness of tropical rain forest canopies, the effects of lateral shading may not be limited to the margins of treefall gaps. Asymmetric crown development also may characterize nongap canopy trees of lower stature that are subject to lateral shading by more prominent neighbors (Young and Hubbell 1991). Canopy trees that do not develop asymmetric crowns in response to lateral shading may simply experience a reduction in their general fitness that leads to a more accelerated demise. If lateral shading among neighboring canopy trees is indeed a cause of reduced fitness or increased vulnerability to windthrow due to uneven distributions of mass in their crowns, then the predictability of canopy tree turnover could be enhanced by identifying those canopy trees subject to the most lateral shading.

Young and Hubbell's (1991) study of the relationship between treefalls and crown asymmetry involved the use of a range finder for ground-based estimates of tree heights and a ground-based survey of the distances between boles and crown edges. Their initial crown map was followed by a reinventory $3.4 \mathrm{yr}$ later. Our study involved the use of high-resolution, large-scale aerial stereophotographs for the determination of the position and dimensions of neighboring canopy tree crowns for computer-based 3-D modeling of lateral shading. Repeat airborne coverage was then acquired for the determination of changes in the sample population of canopy trees over an 18-yr period as a means of assessing the long-term effects of lateral shading. Our research objective was to test the hypothesis that prominent tropical rain forest canopy trees that intercept more direct-beam irradiation have higher survivorship probabilities and crown growth potential than their laterally shaded neighbors.

\section{Methods}

\section{Study area}

The tropical rain forest selected for study is Queensland State Forest No. 452 located on the Atherton Tableland in northeast Queensland, Australia $\left(17^{\circ} 16^{\prime} \mathrm{S}\right.$, $145^{\circ} 35^{\prime}$ E) (Fig. 1). The stand is 258 ha in areal extent, $700 \mathrm{~m}$ above sea level, and locally known as the Curtain Fig Forest (CFF). The Atherton Tableland has been extensively clear cut, and the CFF remains as a protected forest island surrounded by pasture (Fig. 1B). With canopy tree heights ranging between 25 and 42 $m$ (Myers 1982), the structure of the CFF has a greater resemblance to lowland tropical rain forests than to montane rain forests. In the Australian physiognomic classification system (Webb 1959), the CFF is considered a complex notophyll vine forest type (Myers and Benson 1981, Turton 1988) that is more generally defined as a submontane tropical rain forest. Mean annual temperature is $20^{\circ} \mathrm{C}$ (Gordon 1971), and mean annual rainfall is $1400-1600 \mathrm{~mm}$ (Herwitz and Slye 1992). The nutrient-rich krasnozem soils are derived from moderately weathered basalt (Brasell et al. 1980). The section of the CFF examined in our study has a gentle sloping grade of $<5^{\circ}$.

\section{Three-dimensional model of CFF canopy}

In late July 1976, Myers and Benson (1981) conducted a series of overflights in a low-flying aircraft and took aerial photographs (1:1500-1:6000 scale) of the CFF canopy. Their objective was to assess the usefulness of large-scale color stereopairs for tree species identification. Individual canopy tree crowns were readily resolved in the imagery, but interspecific similarities and intraspecific variation in crown morphology as a function of tree age posed formidable problems for reliable species identification. Species were not distinguished in our study because Myers and Benson (1981) reported that only two canopy tree species in the species-rich CFF could be identified with $100 \%$ efficiency.

We used the Myers-Benson stereopairs for the photogrammetric determination of the projected crown 


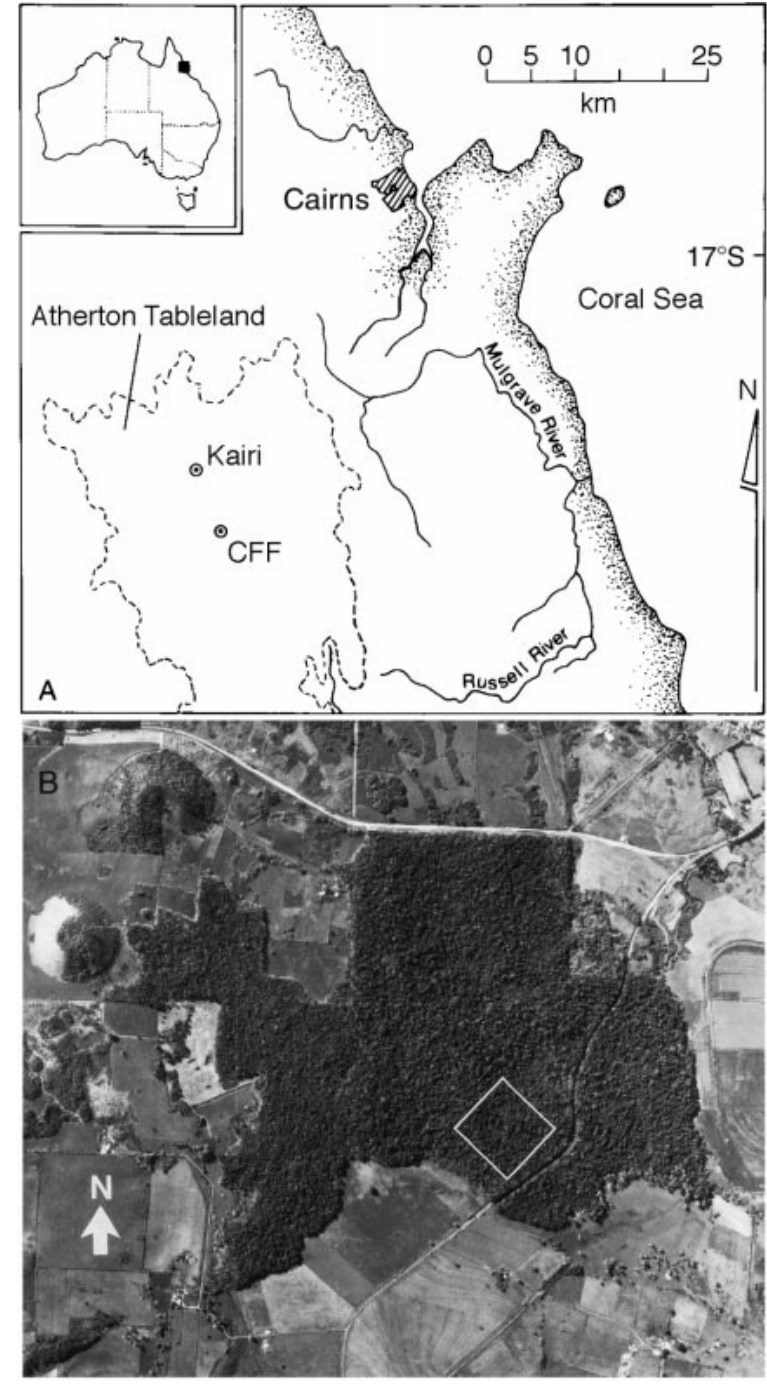

FIG. 1. (A) Location of the Curtain Fig Forest (CFF) and the Kairi Experimental Station on the Atherton Tableland in northeast Queensland, Australia. (B) Aerial view of CFF surrounded by cleared land on the Atherton Tableland; white boxed outline in CFF defines 3.6-ha sample area.

area and crown apex height of each definable canopy tree in a 3.6-ha sample area using a Leica $\mathrm{BC} 1$ analytical stereoplotter (Heerbrugg, Switzerland). The stereopairs were orthorectified using a variety of ground control points (Herwitz et al. 1998). Individual canopy tree crowns were distinguished on the basis of color, texture, and 3-D morphology. Crowns that had minimal aerial exposure or lacked well-defined perimeters were not included.

The $x, y$, and $z$ coordinates representing the canopy tree crown apices were used for the derivation of a triangulated irregular network (Fig. 2A). A lattice grid program developed by Herwitz and Slye (1995) was then used to interpolate a continuous 3-D surface that fitted through the vertex points of each triangle. The result was a discrete, nonlinear, high-resolution 3-D surface comprised of convex-upward parabolic dome shapes representing the canopy tree crowns (Fig. 2B). Pixel size was $0.6 \mathrm{~m}$. The crowns spread downward and outward from each crown apex based on secondorder curves defined by the equation

$$
\Delta z=\left[(\Delta x)^{2}+(\Delta y)^{2}\right] \times 0.02
$$

where $\Delta x$ is the number of rows between a tree's crown apex and any outlying part of its crown, $\Delta y$ is the number of columns between a tree's crown apex and any outlying part of its crown, and $\Delta z$ is the decrease in crown height as a function of distance from the crown apex, with the coefficient 0.02 in units of meters per pixel. The coefficient was selected to best represent a broadly spreading parabolic dome with a gently descending perimeter.

The projected crown area outlines served as a polygon overlay (i.e., stratum mask) that was co-registered with the 3-D model of the canopy surface using shared registration points. The descending parabolic curves radiating from each crown apex were effectively truncated by the irregularly shaped crown perimeters. As a result, crown apices were not always centrally positioned and crown asymmetry was well represented. Unlike the conical shape assumed by Kuuluvainen (1992) for tree crowns with fixed length/width ratios, our model assumed parabolic dome shapes of variable length/width ratios for crowns with non-uniform perimeters.

An important distinction was made between interior and edge trees. Interior trees were surrounded on all sides by neighboring tree's crowns delimited in the stereopairs. Edge trees corresponded to the outer edge of the sample area. Of the 443 canopy trees delimited in the 3.6 ha sample area, 368 were interior trees and the other 75 were edge trees.

\section{Lateral shading simulations}

The daily courses of lateral shading in the horizontal plane of each interior tree's projected crown area was simulated at hourly intervals by applying a ray-tracing program (RTP) to the 3-D canopy model. The RTP computes the number of pixels shaded within the polygon representing each projected crown area as a function of the position of the ray source. Solar elevation angle and solar azimuth for each daylight hour at the CFF was determined using a navigational FORTRAN program that computes the daily courses of solar position as a function of latitude, longitude, time of day, and time of year. The proportion of each canopy tree's orthogonally projected crown area in the path of directbeam irradiation and unobstructed by lateral shadows cast by neighboring canopy trees was given by

$$
C_{\mathrm{e}}=1-\left(C_{\mathrm{s}} / C\right)
$$

where $C$ is the number of pixels comprising the tree's orthogonally projected crown area, $C_{\mathrm{s}}$ is the number of 

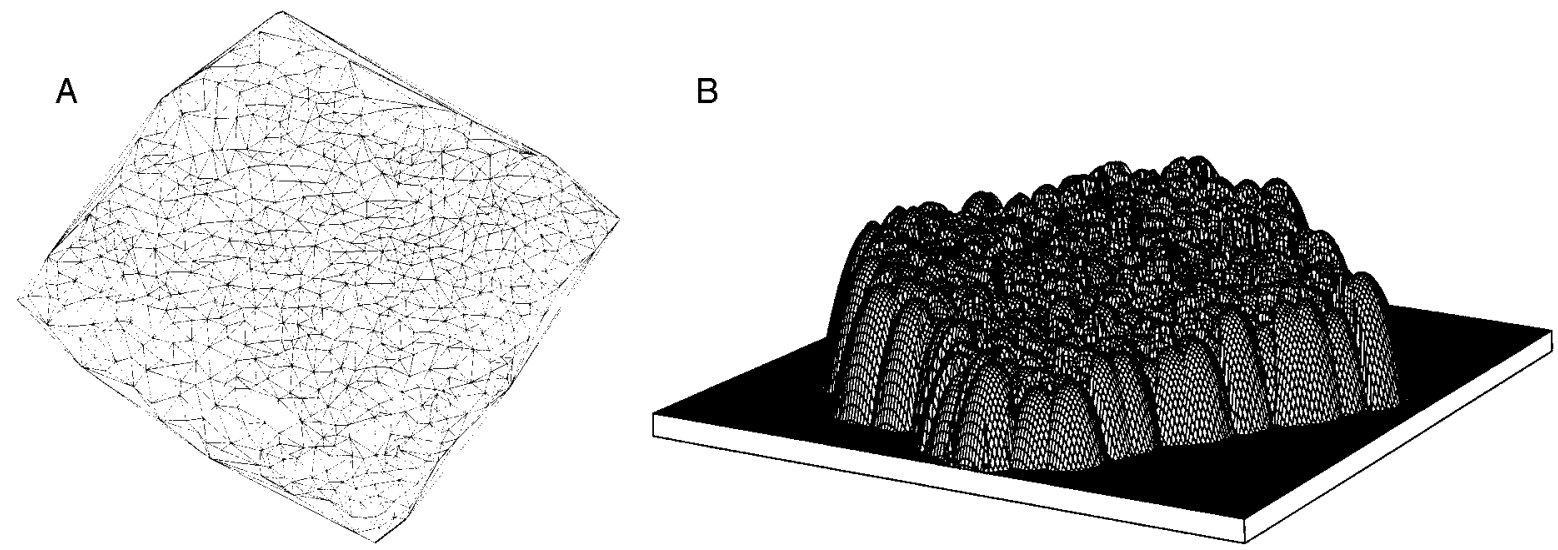

FIG. 2. (A) Triangulated irregular network composed of triangles connecting vertex points of photogrammetrically determined $x, y$, and $z$ coordinates corresponding to canopy tree crown apices. (B) Three-dimensional parabolic-dome model of CFF canopy surface.

shaded pixels in its projected crown area, and $C_{\mathrm{e}}$ is the unshaded proportion of the tree's crown area expressed as a decimal fraction. Edge trees were included as sources of lateral shading for interior trees; however, the $C_{\mathrm{e}}$ values for edge trees were not computed because the complete daily courses of lateral shading that they experienced could not be simulated.

Given the high LAI (leaf area index) of most tropical rain forest canopy trees (Herwitz 1985), our simulations assumed that only a small proportion of the directbeam irradiation passed unintercepted through their crowns. A LAI of $\geq 1.0$ oriented in a horizontal plane through each tree's orthogonally projected crown area was assumed for each daylight hour. When the sun is at its zenith position, $C_{\mathrm{s}}=0.0$ and $C_{\mathrm{e}}=1.0$ for all canopy trees. For canopy trees subject to lateral shadows cast by more prominent neighbors, $C_{\mathrm{e}}<C$. The RTP thus determined the momentary $C_{\mathrm{e}}$ of each tree as a function of solar position. This procedure involved 4745 shaded relief simulation runs to represent each daylight hour over a full calendar year.

\section{Interception of direct-beam irradiation}

The quantity of direct-beam irradiation intercepted by the upper crown surface of each interior tree per unit projected crown area $\left(I_{\mathrm{b}}\right)$ was obtained by multiplying the proportion of unshaded crown area by the available direct-beam irradiation at the corresponding time period. In equation form,

$$
I_{\mathrm{b}}=\left[B_{\mathrm{c}}\left(1-C_{\mathrm{s}} / C\right)\right]=B_{\mathrm{c}} C_{\mathrm{e}}
$$

where $B_{\mathrm{c}}$ is the hourly integral of available cloud-attenuated direct-beam irradiation incident on a horizontal surface above the CFF canopy. Available directbeam irradiation at the CFF was determined using the following procedures.

Hourly integrals of direct-beam and diffuse anisotropic irradiation under cloudless clear-sky conditions were first computed using the Parameterization Model
A program developed by Iqbal (1983). Atmospheric transmissivity varies markedly in the seasonally wet tropics of northeast Queensland, particularly during the wet season when the humidity results in a significant increase in atmospheric turbidity under cloudless skies. The fractions of incident solar energy attenuated by ozone, water vapor, and aerosols under cloudless sky conditions were computed using meteorological data acquired from the Kairi Experimental Station (KES) located on the Atherton Tableland only $7 \mathrm{~km}$ northwest of the CFF at the same elevation above sea level (Fig. 1A). The cloudless sky direct-beam integrals were adjusted to correct for the seasonality of cloud cover using mean monthly daily sunshine duration data recorded at the KES. The available cloud-attenuated direct-beam irradiation $\left(B_{\mathrm{c}}\right)$ incident on the CFF canopy was computed as

$$
B_{\mathrm{c}}=B(n / N)
$$

where $B$ is the hourly direct-beam irradiation under cloudless clear-sky conditions, $n$ is the measured mean monthly daily sunshine duration in hours and $N$ is the maximum possible sunshine hours for the corresponding month based on annual day lengths (Turton 1987). Global irradiation was computed as the sum of the cloud-corrected direct-beam and diffuse-sky values.

The annual total of $B_{\mathrm{c}}$ intercepted by the upper crown surface of each interior canopy tree was used to define its survivorship probability and crown growth potential. Those trees subject to the most lateral shading and intercepting the lower amounts of $B_{\mathrm{c}}$ were expected to have a lower survivorship probability and lower crown growth potential. The prominent canopy trees responsible for lateral shading and intercepting the higher $B_{\mathrm{c}}$ totals were expected to have a higher survivorship probability and greater crown growth potential.

\section{Airborne reinventory in 1994}

The survivorship and crown growth predictions were tested by conducting an airborne reinventory of the 
CFF sample area. In 1994, we replicated the MyersBenson 1976 overflight sequences and acquired a comparable set of large-scale color aerial stereopairs of the same section of the CFF. A similar aircraft equipped with an aerial camera and Kodak aerocolor negative film was used at the same time of year (late July) at the same time of day (late morning). The repeat airborne coverage was used to quantify long-term changes in the sample population of canopy trees delimited in the 1976 stereopairs. The procedure for co-registering the 1994 stereopairs with the Myers-Benson 1976 stereopairs is described by Herwitz et al. (1998).

Canopy tree crown perimeters in both the 1976 and 1994 orthorectified images were digitized for the measurement of canopy tree projected areas. Mortality was determined on the basis of crowns delimited in the 1976 imagery that could not be re-identified in the 1994 imagery. New canopy tree recruits were not included in the 1994 reinventory. The change in the projected area of the exposed upper crown surface of each canopy tree that survived from 1976 to 1994 was used for the quantification of crown growth rates in units of square meters per year. The spatial distribution of the canopy tree crowns and their computed $I_{\mathrm{b}}$ (direct-beam interception totals) were represented by GIS mapping in ArcView (version 3.0).

In 1976, an inventory of trees $\geq 10 \mathrm{~cm}$ dbh (diameter at breast height) conducted in a 0.5 -ha plot located near the center of the 3.6-ha sample area provided measures of the forest stand characteristics from a ground-based perspective. However, due to the closed canopy condition of the multistoried CFF, the trunk corresponding to each tree crown defined in the airborne imagery could not be consistently identified. This finding limited the usefulness of ground-based resampling for evaluating the long-term changes in the CFF canopy.

\section{Statistical analyses}

Logistic regressions were used to determine the relationship between survival and crown area, and the relationship between survival and intercepted directbeam irradiation $\left(I_{\mathrm{b}}\right)$. Differences in the annual $I_{\mathrm{b}}$ totals of the canopy trees that survived over the 18 -yr period and those that died also were evaluated using a oneway analysis of variance (ANOVA).

Survivors were subdivided into two subgroups: those that increased in crown area, and those remained unchanged or experienced a reduction in crown area. Oneway ANOVAs were performed to evaluate whether the annual $I_{\mathrm{b}}$ totals of these two subgroups could explain their different courses of crown area change. The two subgroups were then analyzed separately to identify times of year and times of day when lateral shading may have had the most significant effect on the extent of their respective crown area changes. Correlation coefficients were derived to assess the relationship between their measured crown area changes and their monthly and mean annual hourly $I_{\mathrm{b}}$ totals. Given the
TABLE 1. Stand characteristics of Curtain Fig Forest (CFF) in 1976 based on airborne and ground-based inventories.

\begin{tabular}{lccc}
\hline \hline \multicolumn{1}{c}{ Characteristic } & Mean $( \pm 1 \mathrm{SD})$ & Min. & Max. \\
\hline Airborne inventory $\dagger$ & & & \\
Density (canopy trees/ha) & 123 & $\ldots$ & $\ldots$ \\
Crown elevation (m ASL) & $729.3( \pm 5.3)$ & 716.4 & 741.2 \\
Crown area $\left(\mathrm{m}^{2}\right)$ & $50.3( \pm 41.5)$ & 4.5 & 364.7 \\
Ground-based inventory $\ddagger$ & & & \\
Density (trees/ha) & 624 & $\ldots$ & $\ldots$ \\
Tree height (m) & $16.9( \pm 8.2)$ & 3.0 & 43.0 \\
Dbh $(\mathrm{cm})$ & $29.0( \pm 20.9)$ & 10.0 & 196.5 \\
Basal area $\left(\mathrm{m}^{2} / \mathrm{ha}\right)$ & 63.1 & $\ldots$ & $\ldots$ \\
\hline
\end{tabular}

$\dagger$ Includes interior and edge canopy tree crowns delimited in 3.6-ha sample area.

$\$$ Trees $\geq 10 \mathrm{~cm}$ dbh in CSIRO 0.5-ha permanent plot.

large number of trees considered in the statistical analyses, the significance probability threshold was defined as $<0.01$.

\section{RESULTS}

Forest stand characteristics in 1976

Canopy tree crown elevations in the 1976 stereopairs ranged from 716.4 to $741.2 \mathrm{~m} \mathrm{ASL}$ (above sea level) in the 3.6-ha sample area. The mean crown elevation was $729.3 \mathrm{~m}$ ASL (Table 1). Orthogonally projected crown areas corresponding to the exposed upper surfaces of crowns not overtopped by neighboring trees ranged from 4.5 to $364.7 \mathrm{~m}^{2}$. The mean projected crown area of the delimited interior and edge canopy trees was $50.3 \mathrm{~m}^{2}$.

The stand density of definable canopy trees was 123 trees/ha. This value is very low compared to standard ground-based tropical rain forest inventories of trees $\geq 10 \mathrm{~cm} \mathrm{dbh}$. The ground-based inventory of trees $\geq 10$ $\mathrm{cm} \mathrm{dbh}$ in the 0.5-ha CFF plot yielded a mean dbh of $29.0 \mathrm{~cm}$, estimated tree heights ranging from 3 to 43 $\mathrm{m}$, and a stand density of 624 trees/ha (Table 1 ). In the same 0.5 -ha section of the CFF, 87 canopy trees representing a stand density of 174 trees/ha were delimited using the aerial stereopairs (Herwitz et al. 1998). This difference between airborne and ground-based assessments of stand density indicates that only $28 \%$ of trees $\geq 10 \mathrm{~cm}$ dbh had clearly discernible crowns in upper canopy positions. Fig. 3 shows the spatial distribution of the interior and edge canopy tree crowns in the 3.6ha sample area; the spaces between crowns evident in Fig. 3 contain foliage that could not be assigned to discrete tree crowns.

\section{Lateral shading and differential interception}

The mean annual total of available cloud-attenuated direct-beam irradiation incident on the CFF canopy is $\sim 4.14 \mathrm{GJ} \cdot \mathrm{m}^{-2} \cdot \mathrm{yr}^{-1}$, with a daily average of 11.32 $\mathrm{MJ} \cdot \mathrm{m}^{-2} \cdot \mathrm{d}^{-1}$. Due to the seasonal cloud cover, the mean monthly daily direct-beam irradiation incident on the CFF canopy exceeds diffuse-sky irradiation by 140 $247 \%$. Expressed as a percentage of the predicted an- 


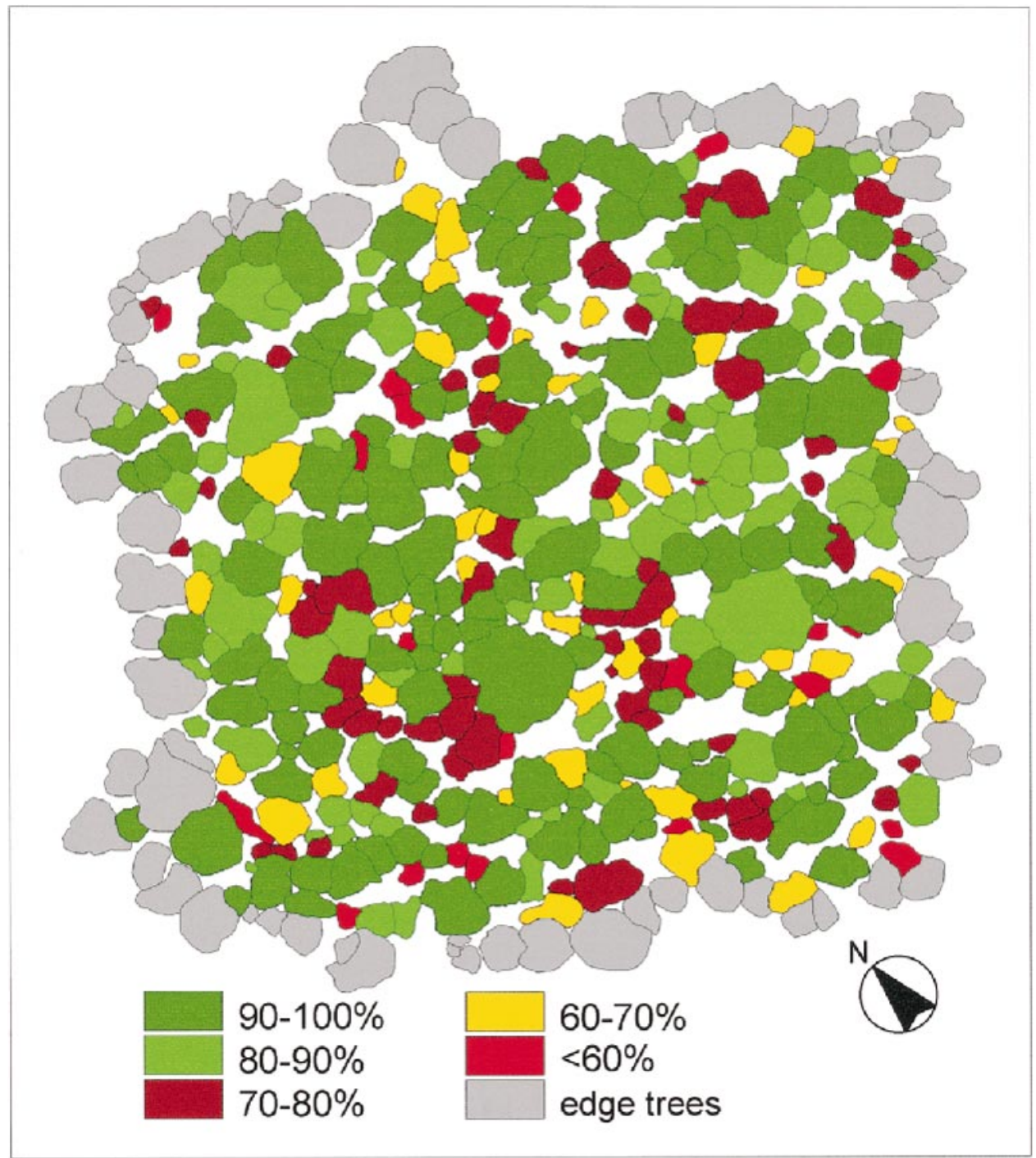

FIG. 3. Map of canopy tree crowns defined in 1976 aerial stereopairs of 3.6-ha CFF sample area showing their mean annual totals of intercepted direct-beam irradiation as percentages of the available incident direct-beam irradiation. The spaces between crowns represent assemblages of partially exposed subcanopy trees with crowns that could not be clearly distinguished.

nual total of incident global irradiation, the direct-beam irradiation amounts to $65.9 \%$ and the diffuse-sky irradiation $34.6 \%$. Differences in the interception of diffuse-sky irradiation among neighboring canopy trees were not considered because they were assumed to be of secondary importance compared to the differences in their direct-beam interception totals.

The annual totals of intercepted direct-beam irradiation $\left(I_{\mathrm{b}}\right)$ ranged from 1.81 to $4.13 \mathrm{GJ} \cdot \mathrm{m}^{-2} \cdot \mathrm{yr}^{-1}$, with a mean annual value $( \pm 1 \mathrm{SD})$ of $3.42 \pm 0.57$ $\mathrm{GJ} \cdot \mathrm{m}^{-2} \cdot \mathrm{yr}^{-1}$. Expressed as a percentage of the available incident direct-beam irradiation, the annual $I_{\mathrm{b}}$ totals ranged from 44 to $100 \%$, with a mean annual value of $83 \pm 14 \%$. Approximately $20 \%$ of the sample population intercepted $\leq 70 \%$ of the available annual directbeam irradiation.
Over the months of November through January when midday solar elevations exceeded $80^{\circ}$, the mean monthly $I_{\mathrm{b}}$ was greater than $86 \%$. During June and July, when midday solar elevations were $<52^{\circ}$, the mean monthly $I_{\mathrm{b}}$ was $<74 \%$ and intertree variation was significantly higher. The higher intertree variation was attributable to prominent canopy trees that continued to intercept high proportions of available direct-beam irradiation at the lower midday solar elevations, and less prominent canopy trees that became more shaded.

The spatial distribution of intertree differences is shown in Fig. 3, with the trees grouped on the basis of their annual $I_{\mathrm{b}}$ totals expressed as percentages of the available direct-beam irradiation. Clusters of canopy trees were defined as involving crowns that either abutted each other at some point along their perimeter or 


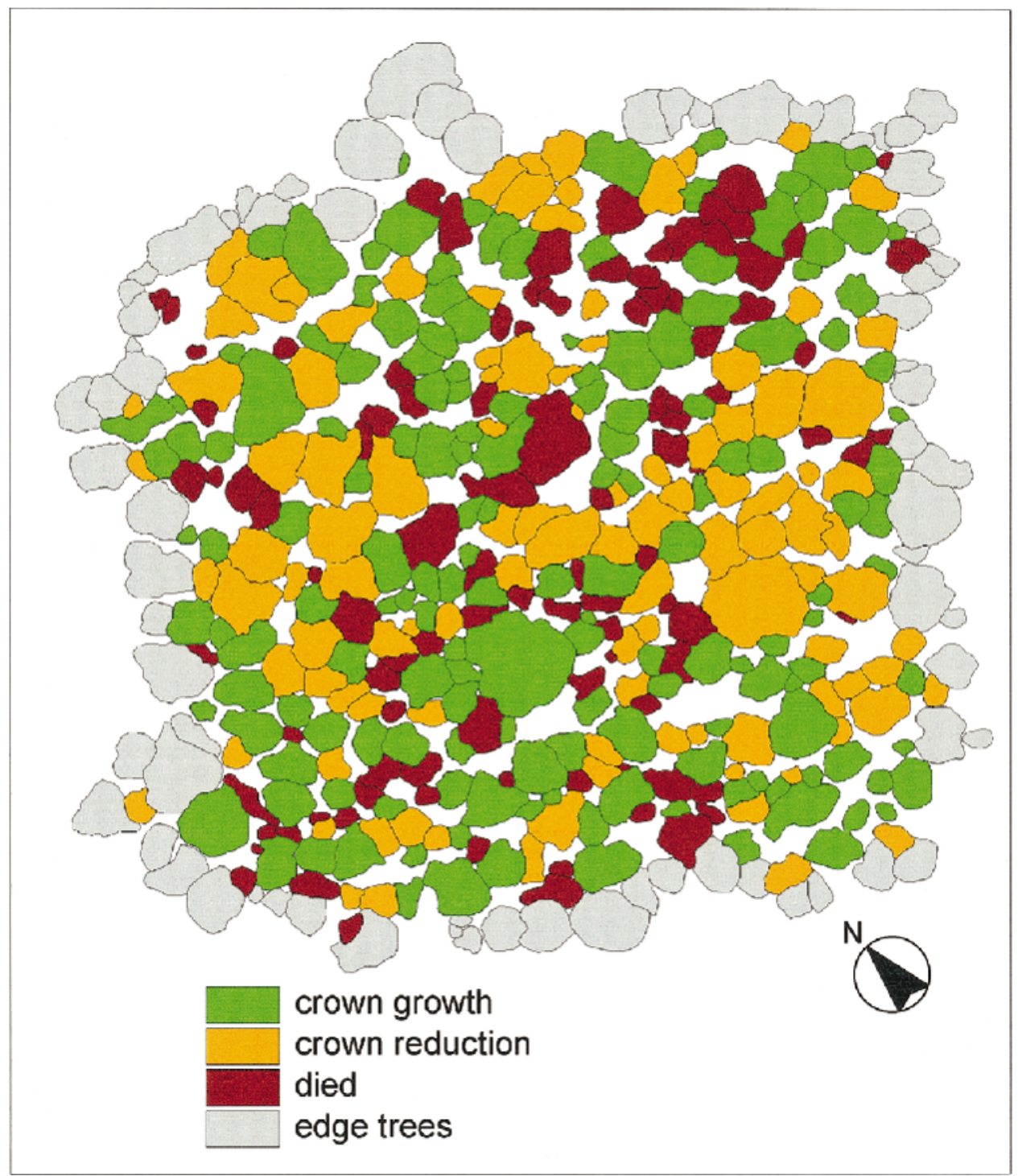

FIG. 4. Map of canopy tree crowns defined in 1976 aerial stereopairs of 3.6-ha CFF sample area showing the spatial distribution patterns of mortality, crown growth, and crown area reduction over the 18-yr period 1976-1994.

were separated by a distance of $<2 \mathrm{~m}$. Of the 24 canopy trees that experienced the most lateral shading and intercepted $<60 \%$ of the available direct-beam irradiation, there were four clustered pairs. Of the 53 canopy trees that intercepted $60-70 \%$, there were three clustered pairs. Clustering of laterally shaded trees may seem counterintuitive because of the assumption that canopy trees, which are themselves laterally shaded, have a limited capacity to shade their neighbors. However, the clusters involved neighboring tree crowns that were progressively shorter in height in directions opposite the solar azimuth. In those cases where the stairstep positioning of neighboring crowns descended toward the solar azimuth, the trees intercepted the same amounts of direct-beam irradiation per unit crown area. Tree height alone, therefore, cannot reliably predict the extent to which a canopy tree will experience lateral shading; rather, it is crown height in relation to the height of neighboring canopy trees that is the determining factor.

\section{Mortality in relation to crown size and lateral shading}

Based on the 1994 airborne reinventory, mortality amounted to $27.2 \%$ of the interior canopy tree population defined in the 1976 imagery (Table 2, Fig. 4). More than $75 \%$ of the canopy trees that died had crown areas of $<40 \mathrm{~m}^{2}$. The 1976 mean crown area of the trees that died was $32.4 \mathrm{~m}^{2}$ compared to the 1976 mean crown area of $54.3 \mathrm{~m}^{2}$ of those that survived. The logistic regression, which was applied to determine the relationship between survival and crown area, revealed 
TABLE 2. Characteristics of interior trees that survived and died over the period 1976-1994. Values shown are means $( \pm 1 \mathrm{SD})$.

\begin{tabular}{lcc}
\hline \hline \multicolumn{1}{c}{ Characteristic } & Survived & Died \\
\hline No. canopy trees delimited in 1976 & $268(72.8 \%)$ & $100(27.2 \%)$ \\
Crown elevation in 1976 (m ASL $) \dagger$ & $729.2 \pm 5.1$ & $730.0 \pm 5.9$ \\
Crown area in 1976 $\left(\mathrm{m}^{2}\right)$ & $54.3 \pm 44.2$ & $32.4 \pm 27.7$ \\
Crown area change, $1976-1994\left(\mathrm{~m}^{2} / \mathrm{yr}\right)$ & $0.4 \pm 1.6$ & $\cdots$ \\
\hline
\end{tabular}

$\dagger \mathrm{ASL}=$ above sea level.

that canopy trees with the smaller, not the larger, crowns had a higher probability of dying $\left(\chi^{2}=29.734\right.$, $P<0.001)$. This finding is contrary to the view that the death rates of trees $\geq 10 \mathrm{~cm}$ dbh in tropical rain forest ecosystems are independent of size class (Clark and Clark 1996).

The relationship between lateral shading and survival was first assessed using a one-way ANOVA to test for differences in the simulated annual totals of direct-beam irradiation intercepted by those trees that survived and those that died. The difference between the survivor and mortality groups was highly significant $(F=11.56, P<0.001)$. Survivors intercepted $3.48 \pm 0.56 \mathrm{GJ} \cdot \mathrm{m}^{-1} \cdot \mathrm{yr}^{-1}$, representing $84 \pm 14 \%$ of the available direct-beam. Those that died intercepted $3.26 \pm 0.56 \mathrm{GJ} \cdot \mathrm{m}^{-2} \cdot \mathrm{yr}^{-1}$, representing $79 \pm 16 \%$. The logistic regression further validated the statistical significance of this difference. Canopy trees with the lower direct-beam irradiation interception totals, as a result of lateral shading, have a higher probability of dying $\left(\chi^{2}=10.981, P<0.001\right)$.

The differences in the mean monthly daily $I_{\mathrm{b}}$ totals of the survivor and mortality groups varied as a function of time of year. The differences were most pronounced over the period June-November (Fig. 5). This period included the lower solar elevation months of June-August as well as the higher solar elevation months of September-November. The greatest mean

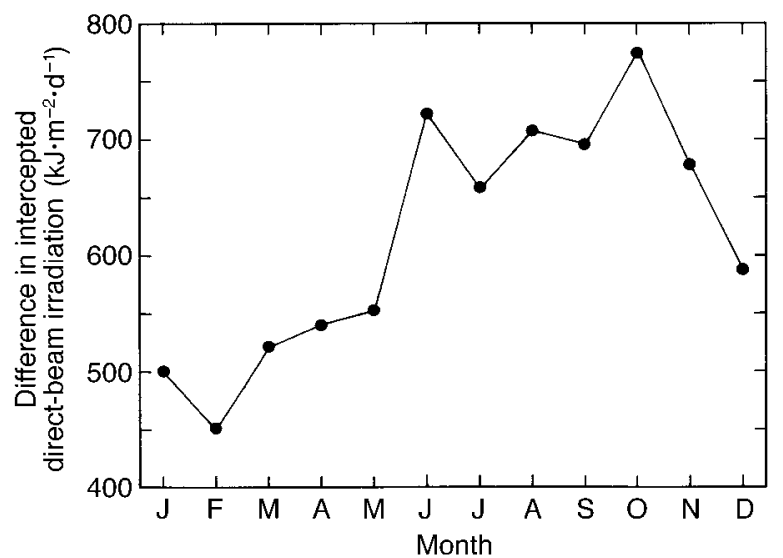

FIG. 5. Monthly mean daily difference in intercepted direct-beam irradiation between the survivor and mortality groups. monthly daily $I_{\mathrm{b}}$ difference between the survivor and mortality groups was $748 \mathrm{~kJ} \cdot \mathrm{m}^{-2} \cdot \mathrm{d}^{-1}$ in October.

\section{Crown area changes in relation to lateral shading}

The change in crown area of the 268 interior canopy trees that survived over the 18 -yr period (mean \pm 1 SD) was $7.6 \pm 29.4 \mathrm{~m}^{2}$. Expressed on an annual basis, the mean rate of crown area change was $0.4 \pm 1.6 \mathrm{~m}^{2} /$ yr (Table 2). This rather low mean rate of change and the wide variation are explained in part by the large number of survivors that experienced crown area reductions. Of the 268 canopy trees that survived, 107 $(39.9 \%)$ experienced crown area reduction (Table 3$)$. An important distinction, therefore, was made between survivors with crown growth (CG) and survivors with crown reduction (CR) (Fig. 4). The mean annual crown growth rate of $\mathrm{CG}$ survivors was $1.3 \mathrm{~m}^{2} / \mathrm{yr}$, while the mean annual rate of crown area reduction for the CR survivors was $-1.0 \mathrm{~m}^{2} / \mathrm{yr}$. From an airborne perspective, decreases in projected crown area could result from encroachment and overtopping by neighboring canopy trees; however, in the CFF sample area, encroachment and overtopping were not the main causes of the crown area reductions. Crown area reductions were most common among the larger, more prominent canopy trees as a result of senescence and branch breakage. In 1976, the CR survivors had a mean crown area of $58.6 \mathrm{~m}^{2}$ compared to the CG survivors, which had a mean crown area of $51.5 \mathrm{~m}^{2}$ (Table 3 ).

Given the $I_{\mathrm{b}}$ differences between the survivor and mortality groups, it would be reasonable to expect a positive correlation between crown area change and $I_{\mathrm{b}}$. However, if a distinction was not made between CG and CR survivors, no significant correlation was found $(P>0.08)$. Based on the one-way ANOVAs, the $I_{\mathrm{b}}$ totals of the CG and CR survivors were not significantly different for any hourly, monthly, or annual time period $(P>0.05)$. The mean annual $I_{\mathrm{b}}$ total of the CG survivors was $84.4 \pm 13.8 \%$ of the available directbeam irradiation, compared to the CR survivors, which intercepted $83.5 \pm 13.3 \%$. Thus, the lateral shading simulations and computed $I_{\mathrm{b}}$ totals failed to predict which surviving canopy trees would experience positive crown growth and which would experience crown area reductions. At first, this finding appears inconsistent with the $I_{\mathrm{b}}$ differences between the survivor and mortality groups. How can lateral shading affect sur- 
TABLE 3. Characteristics of interior canopy trees that survived over the period 1976-1994; characteristics are shown separately for survivors with crown growth and those with crown reduction. Values shown are means ( $\pm 1 \mathrm{SD})$.

\begin{tabular}{lcc}
\hline \hline \multicolumn{1}{c}{ Characteristic } & Crown growth & Crown reduction \\
\hline No. canopy tree survivors, 1976-1994 & $161(60.1 \%)$ & $107(39.9 \%)$ \\
Crown area in 1976 $\left(\mathrm{m}^{2}\right)$ & $51.5 \pm 42.7$ & $58.6 \pm 46.1$ \\
Crown area change, 1976-1994 $\left(\mathrm{m}^{2} / \mathrm{yr}\right)$ & $1.3 \pm 1.3$ & $-1.0 \pm 1.0$ \\
Crown area change, 1976-1994 $(\%)$ & $56.0 \pm 51.8$ & $-29.3 \pm 19.4$ \\
\hline
\end{tabular}

vivorship, but not changes in crown area? The interrelationships between crown position, lateral shading, and crown development became clearer by analyzing the CG and CR survivor groups separately.

For the CG survivors, crown area change was positively correlated with $I_{\mathrm{b}}(r=0.204 ; P<0.01)$. The CR survivors, in contrast, were characterized by a negative correlation between crown area change and $I_{\mathrm{b}}(r$ $=-0.231 ; P<0.01)$. This negative correlation among CR survivors was attributable to the senescent condition of prominent canopy trees that were persisting in upper canopy positions. Subject to higher wind speeds and a higher frequency of branch breakage than their laterally shaded neighbors, prominent canopy trees in the late stage of their life cycle are unable to fully compensate for crown area reductions. Laterally shaded canopy trees are, at least, partially buffered from the crown reducing effects of high windspeeds because they are less exposed to the rigors of full crown exposure than their taller neighbors.

Fig. 6 shows the extent of the crown area changes

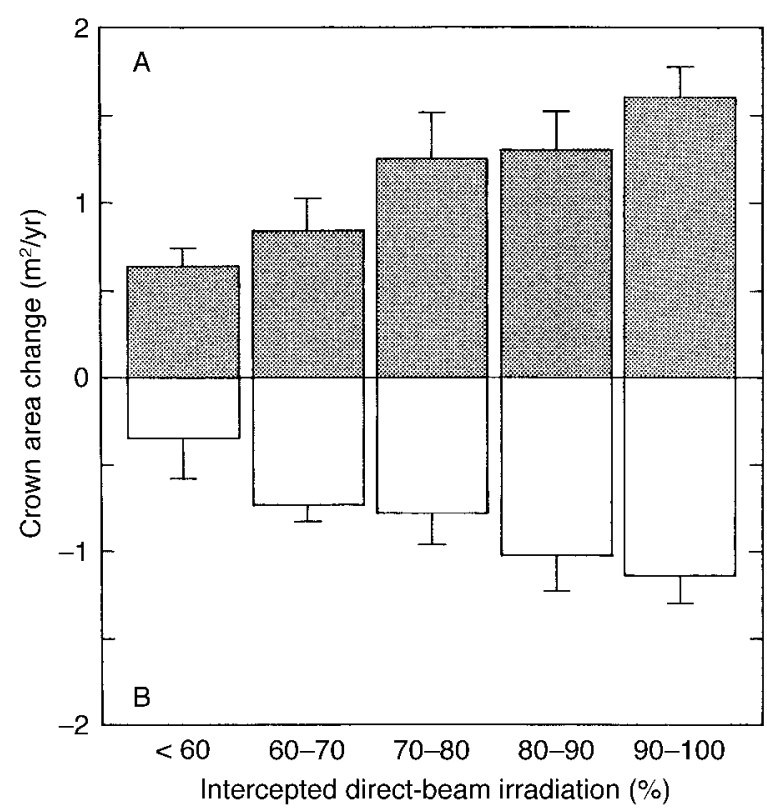

FIG. 6. Mean annual change in projected crown area $( \pm 1$ SE) over the 18-yr period 1976-1994 shown as a function of the mean annual intercepted direct-beam irradiation totals of survivors with (A) crown growth and (B) crown area reductions. for the five $I_{\mathrm{b}}$ groupings mapped in Fig. 3. Prominent canopy trees with the higher $I_{\mathrm{b}}$ totals were at the extremes in terms of both crown growth and crown reduction. Crown area changes of survivors subject to the most lateral shading varied over a much narrower range. The rates of crown growth (Fig. 6A) as well as crown reduction (Fig. 6B) were significantly less for those canopy trees that intercepted $<70 \%$ of the available direct-beam irradiation, compared to those that intercepted $>80 \%$.

\section{Timing of lateral shading}

Seasonal variation in photosynthetic capacities often is a complex system of trade-offs in seasonally wet tropical forests where the cloud cover responsible for the high rainfall totals reduces light availability (Kitajima et al. 1997). To elucidate whether there are seasons or daylight hours when canopy trees might be more adversely affected by lateral shading, the crown area changes of the CG and CR survivors were considered in relation to their monthly mean hourly $I_{\mathrm{b}}$ totals.

Crown growth among CG survivors was positively correlated with $I_{\mathrm{b}}$ mainly through the afternoon hours of 1200-1500 during the months of March-September (Table 4). CG survivors that experienced less lateral shading during this time period tended to have higher crown growth rates, while those that were more laterally shaded had lower crown growth rates. There were some correlations for the other months during some isolated midmorning hours, but they did not represent such a well-defined temporal aggregation of significant correlations (Table 4). Lateral shading may have a more inhibiting effect on crown growth during certain times of day at certain times of year.

Among the CR survivors, those trees with the higher $I_{\mathrm{b}}$ during the later afternoon hours tended to have more pronounced crown area reductions. Significant negative correlations between crown area change and $I_{\mathrm{b}}$ were found for each month (Table 5). The only significant correlation during the morning hours was at 0700 in June. Prominent canopy trees in the late stage of their life cycle are perhaps more adversely affected by full exposure to afternoon direct-beam irradiation. These periods may represent an instance when lateral shading may afford less prominent canopy trees with a greater degree of protection from stresses that would increase their vulnerability to crown reduction. These findings 
TABLE 4. Significance probabilities of positive correlations between crown area changes of crown growth (CG) survivors $(n=161)$ and their monthly mean hourly direct-beam interception totals.

\begin{tabular}{|c|c|c|c|c|c|c|c|c|c|c|c|c|}
\hline \multirow{2}{*}{$\begin{array}{l}\text { Time } \\
\text { of day }\end{array}$} & \multicolumn{12}{|c|}{ Month } \\
\hline & $\mathrm{J}$ & $\mathrm{F}$ & $\mathrm{M}$ & A & $\mathrm{M}$ & $\mathrm{J}$ & $\mathrm{J}$ & $\mathrm{A}$ & $\mathrm{S}$ & $\mathrm{O}$ & $\mathrm{N}$ & $\mathrm{D}$ \\
\hline 0600 & $\ldots$ & $\ldots$ & $\ldots$ & $\ldots$ & $\ldots$ & $\ldots$ & $\ldots$ & $\ldots$ & $\ldots$ & $\ldots$ & $\ldots$ & $\ldots$ \\
\hline 0700 & $\ldots$ & $\ldots$ & $\ldots$ & $\ldots$ & $\ldots$ & $\ldots$ & $\ldots$ & $\ldots$ & $\ldots$ & $\ldots$ & $\ldots$ & $\ldots$ \\
\hline 0800 & $\ldots$ & $\ldots$ & $\ldots$ & $\ldots$ & $\ldots$ & $\ldots$ & $\ldots$ & $\ldots$ & $\ldots$ & $*$ & $*$ & $\ldots$ \\
\hline 0900 & $*$ & $\ldots$ & $\ldots$ & $\ldots$ & $\ldots$ & $\ldots$ & $\ldots$ & $\ldots$ & $\ldots$ & $\ldots$ & $\ldots$ & $*$ \\
\hline 1000 & $\ldots$ & $\ldots$ & $\ldots$ & $\ldots$ & $\ldots$ & $\ldots$ & $\ldots$ & $\ldots$ & $\ldots$ & $\ldots$ & $\ldots$ & $\ldots$ \\
\hline 1100 & $\ldots$ & $\ldots$ & $\ldots$ & $\ldots$ & $\ldots$ & $\ldots$ & $\ldots$ & $\ldots$ & $\ldots$ & $\ldots$ & $\ldots$ & $\ldots$ \\
\hline 1200 & $\ldots$ & $\ldots$ & $\ldots$ & $\ldots$ & $*$ & $*$ & $*$ & $*$ & $\ldots$ & $\ldots$ & $\ldots$ & $\ldots$ \\
\hline 1300 & $\ldots$ & $\ldots$ & $*$ & $*$ & $*$ & $*$ & $*$ & $*$ & $*$ & $\ldots$ & $\ldots$ & $\ldots$ \\
\hline 1400 & $\ldots$ & $\ldots$ & $*$ & $*$ & $*$ & $*$ & $*$ & $*$ & $*$ & $\ldots$ & $\ldots$ & $\ldots$ \\
\hline 1500 & $*$ & $\ldots$ & $*$ & $*$ & $*$ & $*$ & $*$ & $*$ & $*$ & $\ldots$ & $\ldots$ & $\ldots$ \\
\hline 1600 & $\ldots$ & $\ldots$ & $\ldots$ & $\ldots$ & $\ldots$ & $\ldots$ & $\ldots$ & $\ldots$ & $\ldots$ & $\ldots$ & $\ldots$ & $\ldots$ \\
\hline 1700 & $\ldots$ & $\ldots$ & $\ldots$ & $\ldots$ & $\ldots$ & $\ldots$ & $\ldots$ & $\ldots$ & $\ldots$ & $\ldots$ & $\ldots$ & $\ldots$ \\
\hline 1800 & $\ldots$ & $\ldots$ & $\ldots$ & $\ldots$ & $\ldots$ & $\ldots$ &.. & $\ldots$ & $\ldots$ & $\ldots$ & $\ldots$ & $\ldots$ \\
\hline
\end{tabular}

$* P<0.01$. Ellipses $(\cdots)$ indicate nonsignificance.

for the $\mathrm{CG}$ and $\mathrm{CR}$ survivors are suggestive of diurnal and seasonal courses of ecophysiological sensitivity to lateral shading.

\section{DISCUSSION}

\section{Competitive significance of crown position}

The relative heights and sizes of neighboring plants are some of the basic guides used to predict the outcome of their competition for light (Ford and Diggle 1981). In dense assemblages of ground-level annuals and crop monocultures, height advantage often has a positive feedback because of shadows cast on neighboring competitors (Benjamin 1984, Barnes et al. 1990). In uneven-aged tropical rain forest ecosystems, the same principle seems to apply. Prominent canopy trees cast shadows that extend not only vertically downward, but also laterally outward as a function of sun angle. Intercepting direct-beam irradiation and effectively shading neighboring competitors without causing excessive stress to their own leaf temperatures and water status confer tropical rain forest canopy trees with a competitive advantage. Obtaining a dispropor- tionate share of the contested resource (Schwinning and Weiner 1998), they effectively suppress their shorter neighbors.

The probability of a more recently established canopy tree of smaller stature overtopping its taller neighbors is low. Before a canopy tree can generate light depletion zones on its neighbors, it must first cope with lateral shadows and reduced $I_{\mathrm{b}}$ en route to a more prominent position. While their long-term survivorship may exceed that of subcanopy trees, laterally shaded canopy trees have higher mortality rates than their more prominent neighbors. Extensive sympodial branching does not necessarily follow the attainment of an upper canopy position of full exposure to the solar zenith.

Rather than exhibiting a shade avoidance growth response, laterally shaded canopy trees that survive appear to persist in a relatively inhibited state with limited crown area change. The lack of evidence for a dynamic growth response suggests that the development of asymmetric crowns may not be the main cause of death among laterally shaded canopy trees. Although there are difficulties in defining the actual causes of tree

TABLE 5. Significance probabilities of negative correlations between crown area changes of crown reduction (CR) survivors $(n=107)$ and their monthly mean hourly direct-beam interception totals.

\begin{tabular}{|c|c|c|c|c|c|c|c|c|c|c|c|c|}
\hline \multirow{2}{*}{$\begin{array}{l}\text { Time } \\
\text { of day }\end{array}$} & \multicolumn{12}{|c|}{ Month } \\
\hline & $\mathrm{J}$ & $\mathrm{F}$ & $\mathrm{M}$ & A & M & $\mathbf{J}$ & $\mathrm{J}$ & A & $\mathrm{S}$ & $\mathrm{O}$ & $\mathrm{N}$ & $\mathrm{D}$ \\
\hline 0600 & $\ldots$ & $\ldots$ & $\ldots$ & $\ldots$ & $\ldots$ & $\ldots$ & $\ldots$ & $\ldots$ & $\ldots$ & $\ldots$ & $\ldots$ & $\ldots$ \\
\hline 0700 & $\ldots$ & $\ldots$ & $\ldots$ & $\ldots$ & $\ldots$ & $*$ & $\ldots$ & $\ldots$ & $\ldots$ & $\ldots$ & $\ldots$ & $\ldots$ \\
\hline 0800 & $\ldots$ & $\ldots$ & $\ldots$ & $\ldots$ & $\ldots$ & $\ldots$ & $\ldots$ & $\ldots$ & $\ldots$ & $\ldots$ & $\ldots$ & $\ldots$ \\
\hline 0900 & $\ldots$ & $\ldots$ & $\ldots$ & $\ldots$ & $\ldots$ & $\ldots$ & $\ldots$ & $\ldots$ & $\ldots$ & $\ldots$ & $\ldots$ & $\ldots$ \\
\hline 1000 & $\ldots$ & $\ldots$ & $\ldots$ & $\ldots$ & $\ldots$ & $\ldots$ & $\ldots$ & $\ldots$ & $\ldots$ & $\ldots$ & $\ldots$ & $\ldots$ \\
\hline 1100 & $\ldots$ & $\ldots$ & $\ldots$ & $\ldots$ & $\ldots$ & $\ldots$ & $\ldots$ & $\ldots$ & $\ldots$ & $\ldots$ & $\ldots$ & $\ldots$ \\
\hline 1200 & $\ldots$ & $\ldots$ & $\ldots$ & $\ldots$ & $\ldots$ & $\ldots$ & $\ldots$ & $\ldots$ & $\ldots$ & $\ldots$ & $\ldots$ & $\ldots$ \\
\hline 1300 & $\ldots$ & $\ldots$ & $\ldots$ & $\ldots$ & $\ldots$ & $\ldots$ & $\ldots$ & $\ldots$ & $\ldots$ & $*$ & $*$ & $\ldots$ \\
\hline 1400 & $*$ & $*$ & $*$ & $\ldots$ & $\ldots$ & $\ldots$ & $\ldots$ & $\ldots$ & $*$ & $*$ & $*$ & $*$ \\
\hline 1500 & $*$ & $*$ & $*$ & $*$ & $*$ & $*$ & $*$ & $*$ & $*$ & $*$ & $*$ & $*$ \\
\hline 1600 & $*$ & $*$ & $*$ & * & $*$ & $*$ & $*$ & $*$ & $*$ & $*$ & $*$ & $*$ \\
\hline 1700 & $*$ & $*$ & $* *$ & $* *$ & $* *$ & $* *$ & $* *$ & $* *$ & $* *$ & $* *$ & $*$ & $*$ \\
\hline 1800 & $* *$ & $* *$ & $* *$ & $\ldots$ & $\ldots$ & $\ldots$ & $\ldots$ & $\ldots$ & $\ldots$ & $\ldots$ & $\ldots$ & $* *$ \\
\hline
\end{tabular}

$* P<0.01, * * P<0.001$. Ellipses $(\cdots)$ indicate nonsignificance. 
death (Franklin et al. 1987, Pedersen 1998), a more likely explanation is that lateral shading results in decreased productivity and general fitness, and perhaps increased vulnerability to limiting factors such as pathogens. The spatial patterns of canopy tree turnover in tropical rain forest ecosystems may be more predictable than previously thought, but not for the same reasons suggested by Young and Hubbell (1991).

The results of our study indicate: (1) that the effects of lateral shading are not limited to the margins of treefall gaps; (2) that neighboring canopy trees may intercept significantly different amounts of direct-beam irradiation over the course of a year because of lateral shading; and (3) that crown position provides a framework for predicting which canopy trees have the highest probability of surviving and whether those that survive will experience limited or significant changes in crown area. These findings validate the hypothesis that differences in $I_{\mathrm{b}}$ caused by lateral shading have a detectable influence on long-term probabilities of survivorship and crown area change among neighboring canopy trees. The predictive limitation involves identifying which survivors will experience active crown growth and which will experience significant crown reduction. This complication is attributable to prominent canopy trees with high $I_{\mathrm{b}}$ totals that tend to have the largest increases as well as the largest decreases in crown area.

Crown growth was positively correlated with $I_{\mathrm{b}}$ among vigorous prominent canopy trees. Their laterally shaded neighbors, however, were not the trees that experienced the most significant crown area reductions; rather, it was other prominent, but less vigorous, canopy trees in the late stage of their life cycle. These senescent canopy trees suffered branch breakage events from which they did not fully recover with compensatory growth, perhaps because of a reduction in their light utilization efficiency (Björkman and Powles 1984, Lovelock et al. 1994). Nevertheless, they continued to persist, coping with the evaporative demands of the upper canopy (Myers et al. 1987), while continuing to cast lateral shadows. The issue, therefore, is not whether a persistent long-lived canopy tree will experience an increase or decrease in crown area, but rather whether the change in its crown area will be significant or negligible.

Identifying the factors responsible for the spatial patterns of survivorship, growth, and turnover of neighboring plants competing for sunlight is basic to ecological research. There are, of course, limitations in making broad generalizations about the effects of plants on the performance of neighboring plants, even when clear differences in neighbor canopy structure and light interception can be identified (Tremmel and Bazzaz 1993). The factors responsible for variations in growth patterns of canopy trees are complex and may involve unpredictable events and species-specific responses (Clark and Clark 1992, Fisher 1992). One could argue that meaningful models of tropical rain forest dynamics cannot be developed. The fact is that modeling of tropical rain forest dynamics will continue as will the need to identify the factors influencing the long-term performance of canopy trees.

\section{Ground-based and airborne perspectives}

Ground-based repeat censusing of the dbh of tagged trees in permanent plots has been the standard method for quantifying the growth rates and turnover of tree populations in closed canopy tropical rain forest ecosystems. Valuable long-term databases have been acquired on the survivorship, mortality, recruitment, and dbh growth increments of tropical trees (e.g., Lang and Knight 1983, Lieberman and Lieberman 1987, Manokaran and Kochummen 1987, Swaine et al. 1987, Herwitz and Young 1994). This ground-based approach to forest dynamics, however, provides little detail on the development and interactions of neighboring canopy tree crowns competing for direct-beam solar irradiation and vying for more space in the upper canopy. Dbh growth increments provide only indirect measures of crown expansion and no indication of crown area reduction.

Past quantitative assessments of the crown dimensions of canopy trees in closed canopy forests have been approximated by ground-based photography (Koike 1985, McIntire et al. 1990) or ground-based surveying (Oberbauer et al. 1988, Young and Hubbell 1991, Sumida 1995). Tanaka and Nakashizuka (1997) recently demonstrated the usefulness of 1:8000 to 1:20000 scale aerial photographs of a temperate forest for constructing digital elevation models of the canopy surface and determining the long-term spatial dynamics of canopy gaps. Their finding that newly created gaps were biased toward the edge of old gaps validated Young and Hubbell's (1991) conclusion regarding the persistent locations of treefall gaps; however, the scale of their imagery was inadequate for delimiting individual canopy tree crowns.

The procedures and results described in our paper demonstrate the usefulness of co-registered aerial stereopairs at the higher resolution scales of 1:1500 to 1:3000 for 3 -D modeling of canopy tree crowns. The large scale of the georeferenced airborne imagery made it possible to simulate lateral shading and evaluate its long-term effects on an individual tree basis. The position of neighboring tropical rain forest canopy tree crowns appears to be a more important factor influencing their long-term fates than has been previously recognized from a ground-based perspective. It is important to recognize, however, that the actual causes of crown reduction and mortality may not be limited to aboveground interactions. Root competition, for example, may well be a factor responsible for reduced vigor among laterally shaded canopy trees.

Repeat inventories of tropical rain forest tree populations in ground-based permanent plots, with atten- 
tion to belowground interactions, will continue to provide useful databases. We contend that airborne imagery capable of resolving canopy tree crowns can serve as a valuable tool for further enhancing these studies. As remotely sensed imaging technology continues to progress, long-term airborne monitoring of the developmental biology, life histories, and interactions of mature canopy tree crowns will further contribute to our knowledge of tropical rain forest dynamics and the formulation of more meaningful models. The possibility that the influence of lateral shading may vary as a function of time of year and time of day suggests that there may be a definable course of ecophysiological sensitivity that characterizes the tropical rain forest canopy tree populations of Australia. It remains to be determined whether the effects of lateral shading documented in Australia are also applicable to canopy tree populations in other nonequatorial tropical rain forests.

\section{ACKNOWLEDGMENTS}

Thanks to G. Stocker for the site selection and providing the 1976 forest inventory data for the CSIRO 0.5-ha sample plot, B. Myers for sharing the 1976 imagery, R. Peever for assisting with the aerial target field survey, R. Rudd for assisting with the aerial photography in 1994, G. Thelin and D. Aitken for their assistance with the 3-D canopy modeling, and the CSIRO Division of Forest Research for providing access to their canopy tower. The Pascal source codes for our 3 -D canopy model and ray-tracing program are available upon request. This study was funded by NSF grant DEB-9407853 to S. R. Herwitz, R. E. Slye, and S. M. Turton.

\section{Literature Cited}

Augspurger, C. K. 1984. Light requirements of neotropical tree seedlings: a comparative study of growth and survival. Journal of Ecology 77:777-796.

Barnes, P. W., W. Beyschlag, R. Ryel, S. D. Flint, and M. M. Caldwell. 1990. Plant competition for light analyzed with a multispecies canopy model. III. Influence of canopy structure in mixtures and monocultures of wheat and wild oat. Oecologia 82:560-566.

Benjamin, L. R. 1984. Role of foliage habit in the competition between different sized plants in carrot crops. Annals of Botany 53:549-557.

Björkman, O., and S. B. Powles. 1984. Inhibition of photosynthetic reactions under water stress: interaction with light level. Planta 161:490-504.

Brasell, H. M., G. L. Unwin, and G. C. Stocker. 1980. The quantity, temporal distribution and mineral-element content of litterfall in two forest types in tropical Australia. Journal of Ecology 68:123-139.

Canham, C. D., J. S. Denslow, W. J. Platt, J. R. Runkle, T. A. Spies, and P. S. White. 1990. Light regimes beneath closed canopies and tree-fall gaps in temperate and tropical forests. Canadian Journal of Forest Research 20:620-631.

Chazdon, R. L. 1988. Sunflecks and their importance to forest understorey plants. Advances in Ecological Research 18:1-63.

Chazdon, R. L., and N. Fetcher. 1984. Photosynthetic light environments in a lowland tropical rain forest in Costa Rica. Journal of Ecology 72:553-564.

Chazdon, R. L., and R. W. Pearcy. 1986. Photosynthetic responses to light variation in rainforest species. II. Carbon gain and photosynthetic efficiency during lightflecks. Oecologia 69:524-531.

Chazdon, R. L., R. W. Pearcy, D. W. Lee, and N. Fetcher.
1996. Photosynthetic responses to contrasting light environments. Pages 5-55 in S. S. Mulkey, R. L. Chazdon, and A. P. Smith, editors. Tropical forest plant ecophysiology. Chapman and Hall, New York, New York, USA.

Clark, D. B., and D. A. Clark. 1992. Life history diversity of canopy and emergent trees in a neotropical rain forest. Ecological Monographs 62:315-344.

Clark, D. B., and D. A. Clark. 1996. Abundance, growth and mortality of very large trees in neotropical lowland rain forest. Forest Ecology and Management 80:235-244.

Fisher, J. B. 1992. How predictive are computer simulations of tree architecture? International Journal of Plant Science 153:S137-S146.

Ford, E. D., and P. J. Diggle. 1981. Competition for light in a plant monoculture modelled as a spatial stochastic process. Annals of Botany 48:481-500.

Franklin, J. F., H. H. Shugart, and M. Harmon. 1987. Tree death as an ecological process: the causes, consequences and variability of tree mortality. BioScience 37:550-556.

Givinish, T. J. 1984. Leaf and canopy adaptations in tropical forests. Pages 51-84 in E. Medina, H. A. Mooney, and C. Vasquez-Yanes, editors. Physiological ecology of plants of the wet tropics. Dr. W. Junk, The Hague, The Netherlands.

Givinish, T. J. 1988. Adaptation to sun and shade: a wholeplant perspective. Australian Journal of Plant Physiology 15:63-92.

Gordon, B. 1971. Climatic survey northern region 16Queensland, Bureau of Meteorology, Department of the Interior, Commonwealth of Australia.

Herwitz, S. R. 1985. Interception storage capacities of tropical rainforest canopy trees. Journal of Hydrology 77:237252.

Herwitz, S. R., and R. E. Slye. 1992. Spatial variation in the interception of inclined rainfall by a tropical rainforest canopy. Selbyana 13:62-71.

Herwitz, S. R., and R. E. Slye. 1995. Three-dimensional modeling of canopy tree interception of wind-driven rainfall. Journal of Hydrology 168:205-226.

Herwitz, S. R., R. E. Slye, and S. M. Turton. 1998. Coregistered aerial stereopairs from low-flying aircraft for the analysis of long-term tropical rainforest canopy dynamics. Photogrammetric Engineering and Remote Sensing 64: 397-405.

Herwitz, S. R., and S. Young. 1994. Mortality, recruitment, and growth rates of montane tropical rainforest canopy trees on Mount Bellenden-Ker, northeast Queensland, Australia. Biotropica 26:350-361.

Iqbal, M. 1983. An introduction to solar radiation. Academic Press, New York, New York, USA.

King, D. A. 1994. Influence of light level on the growth and morphology of saplings in a Panamanian forest. American Journal of Botany 81:948-957.

Kitajima, K., S. S. Mulkey, and S. J. Wright. 1997. Seasonal phenotypes in the canopy of a tropical dry forest: photosynthetic characteristics and associated traits. Oecologia 109:490-498.

Koike, F. 1985. Reconstruction of two-dimensional tree and canopy profiles using photographs. Journal of Applied Ecology 22:921-929.

Kuuluvainen, T. 1992. Tree architectures adapted to efficient light utilization: is there a basis for latitudinal gradients? Oikos 65:275-284.

Kuuluvainen, T., and T. Pukkala. 1987. Effect of crown shape and tree distribution on the spatial distribution of shade. Agricultural and Forest Meteorology 40:215-231.

Lang, G. E., and D. H. Knight. 1983. Tree growth, mortality, recruitment, and canopy gap formation during a 10-year period in a tropical moist forest. Ecology 64:1075-1080.

Langenheim, J. H., C. B. Osmond, A. Brooks, and P. J. Ferrar. 1984. Photosynthetic responses to light in seedlings of se- 
lected Amazonian and Australian rainforest tree species. Oecologia 63:215-224.

Lawton, R. O., and F. E. Putz. 1988. Natural disturbance and gap-phase regeneration in a wind-exposed tropical cloud forest. Ecology 69:764-777.

Lieberman, D., and M. Lieberman. 1987. Forest tree growth and dynamics at La Selva, Costa Rica (1969-1982). Journal of Tropical Ecology 3:347-358.

Longman, K. A., and J. Jeník. 1974. Tropical forest and its environment. Longman, Essex, UK.

Lovelock, C. E., M. Jebb, and C. B. Osmond. 1994. Photoinhibition and recovery in tropical plant species: response to disturbance. Oecologia 97:297-307.

Manokaran, N., and K. M. Kochummen. 1987. Recruitment, growth and mortality of tree species in a lowland dipterocarp forest in Peninsular Malaysia. Journal of Tropical Ecology 3:315-330.

McIntire, B. M., M. A. Scholl, and J. T. Sigmon. 1990. A quantitative description of a deciduous forest canopy using a photographic technique. Forest Science 36:381-393.

Myers, B. J. 1982. Guide to the identification of some tropical rainforest species from large-scale colour aerial photographs. Australian Forestry 45:28-41.

Myers, B. J., and M. L. Benson. 1981. Rainforest species on large-scale color photos. Photogrammetric Engineering and Remote Sensing 47:505-513.

Myers, B. J., R. H. Robichaux, G. L. Unwin, and I. E. Craig. 1987. Leaf water relations and anatomy of a tropical rainforest tree species vary with crown position. Oecologia 74: $81-85$.

Oberbauer, S. F., D. B. Clark, D. A. Clark, and M. Quesada. 1988. Crown light environments of saplings of two species of rain forest emergent trees. Oecologia 75:207-212.

Oberbauer, S. F., and B. R. Strain. 1986. Effects of canopy position and irradiance on the leaf physiology and morphology of Pentaclethra macroloba (Mimosaceae). American Journal of Botany 73:409-416.

Oldeman, R. A. A. 1978. Architecture and energy exchange of dicotyledonous trees in the forest. Pages 535-560 in P. B. Tomlinson and M. H. Zimmermann, editors. Tropical trees as living systems. Cambridge University Press, Cambridge, UK.

Pearcy, R. W. 1990. Sun flecks and photosynthesis in plant canopies. Annual Review of Plant Physiology and Plant Molecular Biology 41:421-453.
Pearcy, R. W., and W. Yang. 1996. A three-dimensional crown architectural model for assessment of light capture and carbon gain by understory plants. Oecologia 108:112.

Pedersen, B. S. 1998. The role of stress in the mortality of midwestern oaks as indicated by growth prior to death. Ecology 79:79-93.

Pinker, R. T., and J. Z. Holland. 1988. Turbulence structure of a tropical forest. Boundary-Layer Meteorology 43:4363.

Richards, P. W. 1952. The tropical rain forest. Cambridge University Press, Cambridge, UK.

Schwinning, S., and J. Weiner. 1998. Mechanisms determining the degree of size asymmetry in competition among plants. Oecologia 113:447-455.

Smith, A. P., K. P. Hogan, and J. R. Idol. 1992. Spatial and temporal patterns of light and canopy structure in a lowland tropical moist forest. Biotropica 24:503-511.

Sumida, A. 1995. Three-dimensional structure of a mixed broad-leaved forest in Japan. Vegetatio 119:67-80.

Swaine, M. D., J. B. Hall, and I. J. Alexander. 1987. Tree population dynamics at Kade, Ghana (1968-1982). Journal of Tropical Ecology 3:331-345.

Tanaka, H., and T. Nakashizuka. 1997. Fifteen years of canopy dynamics analyzed by aerial photographs in a temperate deciduous forest, Japan. Ecology 78:612-620.

Tremmel, D. C., and F. A. Bazzaz. 1993. How neighbor canopy architecture affects target plant performance. Ecology 74:2114-2124.

Turton, S. M. 1987. The relationship between total irradiation and sunshine duration in the humid tropics. Solar Energy 38:353-354.

Turton, S. M. 1988. Solar radiation regimes in a north Queensland rainforest. Proceedings of the Ecological Society of Australia 15:101-105.

Webb, L. J. 1959. A physiognomic classification of Australian rain forests. Journal of Ecology 47:551-572.

Yates, D. J., G. L. Unwin, and D. Doley. 1988. Rainforest environment and physiology. Proceedings of the Ecological Society of Australia 15:31-37.

Young, T. P., and S. P. Hubbell. 1991. Crown asymmetry, treefalls, and repeat disturbance of broad-leaved forest gaps. Ecology 72:1464-1471.

Young, T. P., and V. Perkocha. 1994. Treefalls, crown asymmetry and buttresses. Journal of Ecology 82:319-324. 